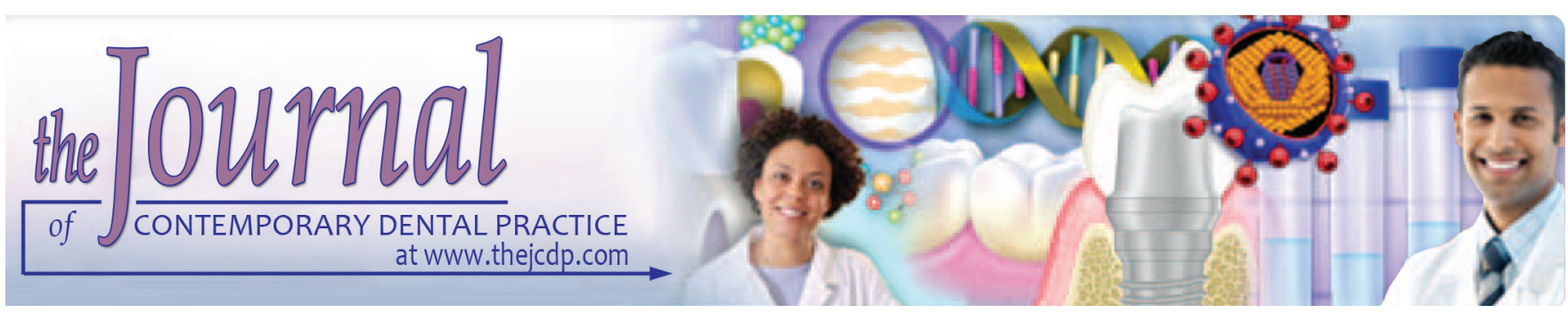

\title{
Fracture Strength of Endodontically treated Maxillary Central Incisors restored with Nickel Chromium and Nonprecious Gold Alloy Casting Post and Cores
}

\footnotetext{
${ }^{1}$ Hassan A Khiavi, ${ }^{2}$ Sareh Habibzadeh, ${ }^{3}$ Shima Safaeian, ${ }^{4}$ Mahsa Eftekhar
}

\begin{abstract}
Aim: Since fiber posts are not recommended for teeth under lateral loads, a new alloy containing $>80 \%$ copper (nonprecious gold or NPG) was introduced with a modulus of elasticity closer to that of dentin and easier preparation. This study aimed to compare the fracture strength of endodontically treated maxillary central incisors restored with nickel chromium ( $\mathrm{Ni}-\mathrm{Cr}$ ) and NPG alloys.
\end{abstract}

Materials and methods: Casting post and cores were fabricated of Ni-Cr and NPG alloys for 24 maxillary central incisors $(n=12)$. Full-metal crowns were also fabricated and placed under cyclin loading in $30 \mathrm{~N}$ load and $45^{\circ}$ angle, for 250,000 cycles with $2.6 \mathrm{~Hz}$ frequency. The fracture strength was measured at a crosshead speed of $0.5 \mathrm{~mm} / \mathrm{min}$ and $135^{\circ}$ angle in a universal testing machine. Data were analyzed using independent t-test

Results: The mean fracture strength was $731.179 \pm 327.47$ and $1411.89 \pm 313.56 \mathrm{~N}$ in the $\mathrm{Ni}-\mathrm{Cr}$ and NPG groups respectively; this difference was statistically significant $(p<0.001)$. The fracture was irreparable in all teeth since the fracture line was below the cementoenamel junction (CEJ).

Conclusion: The fracture strength of teeth restored with cast NPG post and cores was significantly higher than that of teeth restored with cast $\mathrm{Ni}-\mathrm{Cr}$ post and cores.

Clinical significance: Due to proper mechanical properties, NPG post and cores seem to be a suitable choice for restoration of severely damaged anterior teeth, provided that other properties are proven to be acceptable.

\footnotetext{
${ }^{1-4}$ Department of Prosthodontics, Tehran University of Medical Sciences, International Campus, School of Dentistry, Tehran Islamic Republic of Iran

Corresponding Author: Sareh Habibzadeh, Department of Prosthodontics, Tehran University of Medical Sciences International Campus, School of Dentistry, Tehran, Islamic Republic of Iran, Phone: +989125212758, e-mail: sareh. habibzadeh@gmail.com/s-habibzadeh@tums.ac.ir
}

Keywords: Endodontically treated teeth, Fracture strength, Nonprecious gold alloy, Post and core.

How to cite this article: Khiavi HA, Habibzadeh S, Safaeian S, Eftekhar M. Fracture Strength of Endodontically treated Maxillary Central Incisors restored with Nickel Chromium and Nonprecious Gold Alloy Casting Post and Cores. J Contemp Dent Pract 2018;19(5):560-567.

Source of support: Nil

Conflict of interest: None

\section{INTRODUCTION}

Endodontic treatment and subsequent prosthetic reconstruction are the suggested treatment plan for teeth that have lost a great portion of their structure. ${ }^{1-5}$ Loss of coronal tooth structure due to caries, previous restoration, and root weakness due to excessive dentin removal during root canal cleaning and shaping, ${ }^{6-8}$ increase the tooth susceptibility to fracture. ${ }^{9-12}$ Thus, post and core treatment followed by crown coverage is the suggested treatment plan for teeth with moderate-to-severe loss of tooth structure. ${ }^{13-15}$

Various types of post systems have been suggested for the restoration of endodontically treated teeth. The difference between the modulus of elasticity of the post and dentin can apply stress to root structure. ${ }^{16}$ Using a post with a modulus of elasticity similar to that of dentin can result in a more favorable biomechanical function. Thus, glass fiber posts have been the topic of new studies; ${ }^{17}$ however, casting posts remain the method of choice for the restoration of anterior teeth with moderate-to-severe loss of tooth structure. ${ }^{15,18}$ Several studies have shown that the fracture strength of teeth reconstructed with casting posts was higher than that of teeth restored with glass fiber posts. In long-term follow-ups, failure rate of fiber posts was more than twice the rate for conventionally cemented 
titanium posts and casting posts. ${ }^{19,20}$ Optimal adaptation of post to the prepared post space ${ }^{15,21-25}$ and subsequent better stress distribution ${ }^{25}$ are among other advantages of the conventional casting post and cores. Moreover, casting posts require less canal preparation and widening compared with prefabricated posts; this advantage can decrease the risk of root perforation. ${ }^{26}$ Aside from the aforementioned advantages, casting post and cores have disadvantages as well. A systematic review summarized them to be the time-consuming nature of treatment for both patient and technician, high cost, ${ }^{27}$ and technique complexity. ${ }^{12}$ Another thing is their high modulus of elasticity, leading to transfer loads directly from the post to the tooth interface, without shock absorption, resulting in fracture. ${ }^{28,29}$ Irreparable fracture in the remaining tooth structure often occurs with these posts, ${ }^{13,30-32}$ which is among the most common reasons for failure of casting metal posts. ${ }^{33}$ However, Rathke and Meisohle ${ }^{34}$ showed that metal rigid posts were superior to nonmetal posts.

Nickel-chromium is among the most commonly used alloys for the fabrication of casting posts and cores. Hayashi et $\mathrm{al}^{35}$ demonstrated that teeth restored with $\mathrm{Ni}-\mathrm{Cr}$ posts had significantly higher fracture strength and lower risk of vertical root fracture than other groups. Sadeghi ${ }^{29}$ indicated that maxillary canine teeth restored with casting $\mathrm{Ni}-\mathrm{Cr}$ post and cores had a higher mean fracture strength than those restored with zirconia and quartz fiber posts; however, the fracture type in this group was irreparable. Difficult finishing and polishing are another limitation of this alloy. ${ }^{30}$ Despite these disadvantages, $\mathrm{Ni}-\mathrm{Cr}$ alloy is still the most commonly used alloy for the fabrication of casting post and cores. ${ }^{34}$

Recently, NPG alloy has been used for the fabrication of posts and cores. It has a closer modulus of elasticity to that of dentin. The NPG alloy was introduced in $1987 .{ }^{35}$ This alloy contains more than $80 \%$ copper and is known as NPG alloy. ${ }^{5}$ It has been claimed that the NPG alloy has optimal physical and mechanical properties for endodontic posts and has a much easier preparation and handling than Ni-Cr posts. ${ }^{35,36}$ However, studies on the fracture strength of teeth restored with NPG posts are limited. ${ }^{23}$ This study aimed to compare Ni-Cr and NPG posts and their effect on the fracture strength of endodontically treated teeth.

\section{MATERIALS AND METHODS}

A total of 24 maxillary central incisors were randomly divided into two groups $(n=12)$. Teeth with cracks, previous endodontic treatment, those with restorations or severe caries were excluded. ${ }^{18,37-39}$ Maxillary central incisors with the following dimensions were chosen:

- Root length: $13 \pm 1 \mathrm{~mm}$

- Mesiodistal width of tooth crown at the height of contour: $8.5 \pm 1 \mathrm{~mm}$
- Labiolingual width of tooth crown at the height of contour: $7 \pm 1 \mathrm{~mm}$

- Mesiodistal width of root at the CEJ: $6.3 \pm 0.5 \mathrm{~mm}$

- Labiolingual width of root at the CEJ: $6 \pm 0.4 \mathrm{~mm}^{40,41}$

Prior to testing, the extracted teeth were immersed in $5.25 \%$ sodium hypochlorite for 24 hours $^{33}$ and were then stored in saline at room temperature ${ }^{40,42-44}$ for less than 3 months until the experiment. ${ }^{38,45,46}$

\section{Root Canal Treatment}

Access cavity was prepared using high-speed hand piece and long-shaft diamond bur (Teeskavan, Iran) under water coolant. ${ }^{23}$ According to the standard method, root canals were cleaned and shaped using $\mathrm{K}$ files (Mani, Tochigi, Japan) up to size $40.5,25,33,47$ The working length was determined as $1 \mathrm{~mm}$ short of the apex. ${ }^{5,48-50}$ Canals were irrigated with $5.25 \%$ sodium hypochlorite $\mathrm{s}^{23,50-52}$ and then rinsed with saline, dried with paper point (Sinadent, Iran), 38,42 and finally obturated with gutta-percha (Orca; Tiagin, China) and AH26 sealer (Dentsply, Ash, Germany) $)^{5,46,52,53}$ using the lateral condensation technique. ${ }^{5,18,29,42}$

\section{Periodontal Ligament Simulation and Mounting of Specimens}

Roots were embedded in melted wax (Cavex) to $2 \mathrm{~mm}$ beneath the cervical line to obtain 0.2 to $0.3 \mathrm{~mm}$ wax thickness. $5,23,45,54$ The teeth were then mounted in acrylic blocks (Pekatray; Bayer, Leverkuser, Germany) so that $2 \mathrm{~mm}$ of the cervical part of the root remained out of the acrylic block (to maintain the biologic width). 5,23,45,50,54,55 Wax was removed from the root surface and the remaining space between the root and acrylic block was filled with thin silicon (Speedex, Colten AG, Altstattea, Switzerland). This thin silicon layer simulated the periodontal ligament. $5,23,52,54$ The teeth were mounted in resin blocks (Acropars, Iran) so that the longitudinal axis of each tooth remained parallel to the longitudinal axis of the block and the middle part of the CEJ was $2 \mathrm{~mm}$ coronal to the acrylic resin. ${ }^{18,46,49}$

The tooth crowns in groups I and II were then cut perpendicular to the longitudinal axis of the tooth using a hand piece with a diamond disk (Monotrac, Salt Lake City, Utah, USA) under adequate water irrigation $2 \mathrm{~mm}$ above the CEJ. ${ }^{5,18,42,44,46,55,56}$

\section{Fabrication of Casting Post and Cores}

Gutta-percha was removed from the canal using \#2 and \#3 peeso reamers (Mani, Tochigi, Japan) ${ }^{5,42,44}$ so that $4 \mathrm{~mm}$ of gutta-percha remained in the apical portion. $3,18,48$ Root canals were then standardized using \#1 and 2 fiber post tapered drills (Premier, Italy) to a maximum size of $1.4 \mathrm{~mm} .{ }^{42,57}$ 


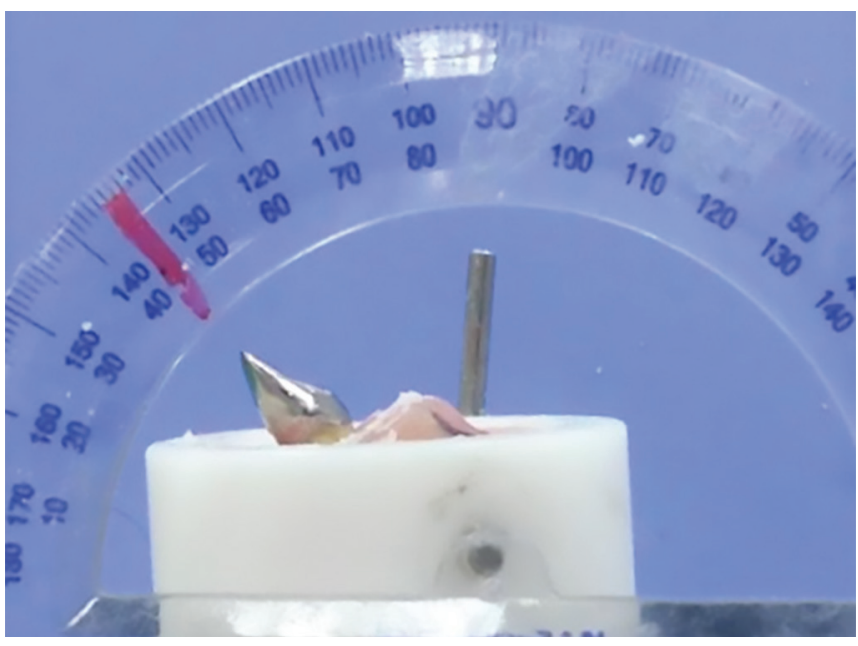

Fig. 1: Remounting at $45^{\circ}$ angle

Casting posts were fabricated using the direct technique. Resin patterns were made using self-cure acrylic resin (Duralay, USA) 3,29,55,56,58,59 and pin jet (Angelus, Brazil). ${ }^{59}$ The cores were then made as follows: a $0.7 \mathrm{~mm}$ labial and lingual tooth reduction was performed. ${ }^{60}$ The remaining mesiodistal and labiolingual width was 5.5 and $4.5 \mathrm{~mm}$ respectively, and occlusogingival length was set to $8 \mathrm{~mm} .^{40}$

\section{Casting of Post and Cores and Cementation}

All specimens were sprued (Dandiran, Tehran, Iran) and invested (Z4, Belgium) using the standard technique. Machine casting with Ni-Cr alloy (Supercast, USA) and NPG (Albadent, USA) was performed for each group. After removing the specimens from the investment and sandblasting, their seating and fit were checked using Occlude fit checker (Pascal, USA) and confirmed radiographically. ${ }^{61}$ After ensuring the complete seating, the post and cores were cemented with self-cure glass ionomer cement (GC, Tokyo, Japan). 3,61 The cement was taken into the canal using a Lentulo (Mani, Tochigi, Japan). 5,29,56

\section{Tooth Preparation for Crown}

Full-metal crown $3,12,42,43,55$ was fabricated with $1.5 \mathrm{~mm}$ occlusal thickness. A $1 \mathrm{~mm}$ depth chamfer was prepared, internal angles were beveled, and unsupported enamel was removed. ${ }^{60}$ Contra-bevel preparation was made around the external border by a diamond bur to create a metal collar around the occlusal surface. This would prevent fracture of the remaining tooth structure. ${ }^{51}$ All specimens were waxed up using the standard technique. ${ }^{41}$ A stop was designed in the wax-up to the palatal surface to stabilize the site for further load application to the crown. ${ }^{42,62}$ The casting process was performed. All crowns were then cemented with self-cure glass ionomer cement (GC Company, Tokyo, Japan). ${ }^{18,63}$

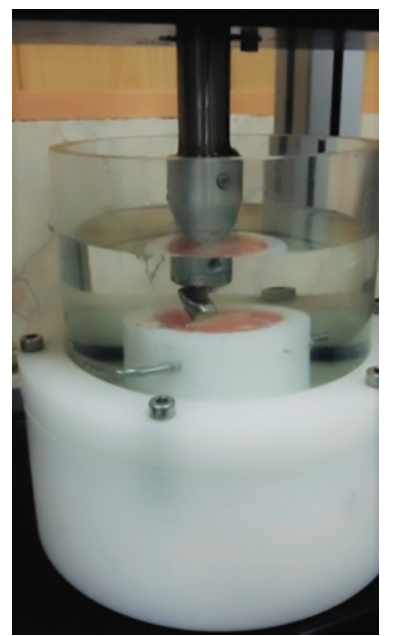

Fig. 2: Cyclic loading in distilled water

\section{Cyclic Loading (Chewing Simulator)}

In the oral environment, anterior teeth are often inclined with $45^{\circ}$ angle. ${ }^{12}$ Thus, the specimens were mounted in the chewing simulator (Germany) with $45^{\circ}$ angle for cyclic loading using auto-polymerizing acrylic resin (Acropars, Iran) (Fig. 1). ${ }^{29}$ After setting the acryl, mounted specimens were fixed in saline containers and subjected to 250,000 cycles with $2.6 \mathrm{~Hz}$ frequency and $30 \mathrm{~N}$ load. ${ }^{62,64-66}$ The load was applied $3 \mathrm{~mm}$ below the incisal edge. ${ }^{12,49}$ The applied load corresponded to 1 year of clinical service (Fig. 2). ${ }^{62,64}$

\section{Static Loading}

The specimens were subjected to static load at a crosshead speed of $0.5 \mathrm{~mm} / \mathrm{min}^{12,42,44,67}$ at $135^{\circ}$ angle until failure in a universal testing machine. ${ }^{62,67,68}$ Type of fracture was also registered. All procedures were performed by one operator for both groups (Fig. 3).

The t-test was used to compare the mean fracture strength between Ni-Cr and NPG groups; $\mathrm{p}<0.05$ was considered statistically significant.

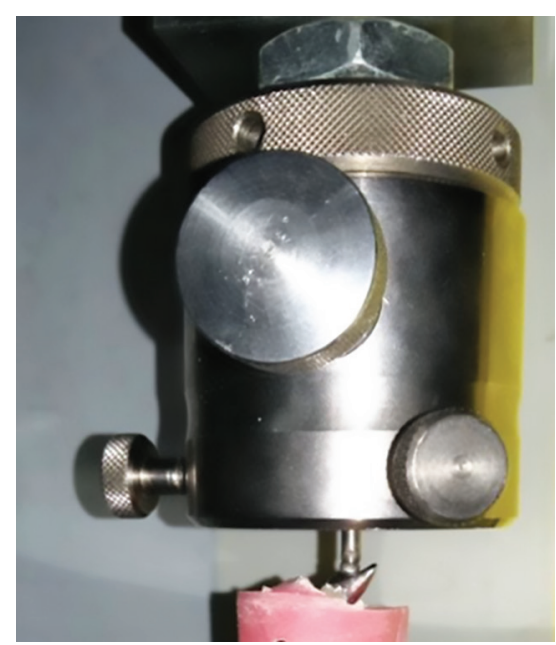

Fig. 3: Static loading 


\begin{tabular}{cll}
\multicolumn{3}{c}{$\begin{array}{c}\text { Table 1: Fracture strength (N) of endodontically treated teeth } \\
\text { restored with NPG and Ni-Cr post and cores }\end{array}$} \\
$\begin{array}{cll}\text { Specimen } \\
\text { number }\end{array}$ & Fracture strength of & Fracture strength of \\
Ni-Cr post and cores & NPG post and cores \\
\hline 1 & - & $1,702.77$ \\
2 & - & $1,610.69$ \\
3 & 569.91 & $1,229.47$ \\
4 & 516.86 & $1,832.18$ \\
5 & 383.58 & $1,762.27$ \\
6 & $1,069.88$ & 814.13 \\
7 & 961.08 & $1,703.48$ \\
8 & 624.03 & $1,035.28$ \\
9 & 399.63 & $1,372.30$ \\
10 & 625.46 & $1,428.85$ \\
11 & $1,418.27$ & $1,227.14$ \\
12 & 743.09 & $1,521.44$ \\
\hline
\end{tabular}

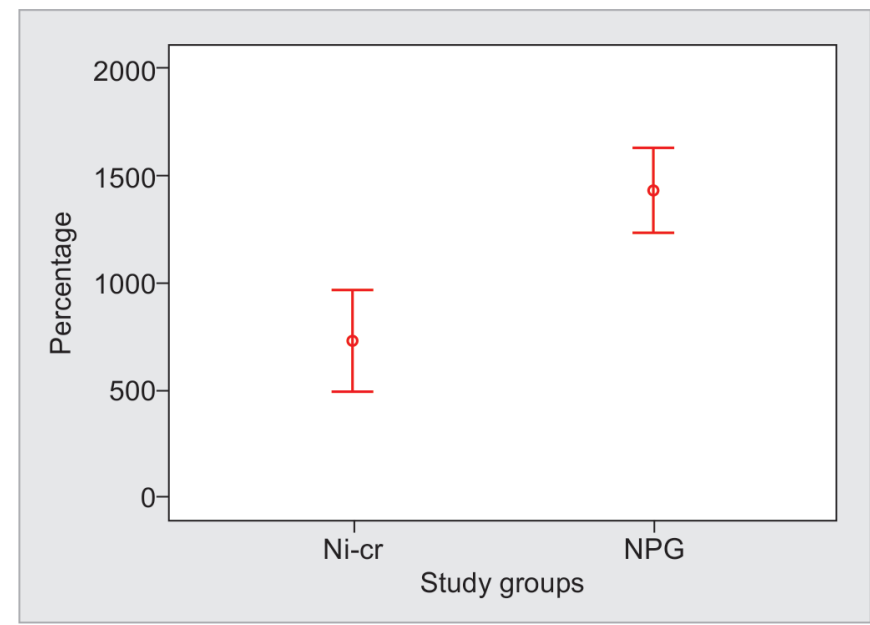

Graph 1: Comparison of fracture strength of Ni-Cr and NPG groups with $95 \%$ confidence interval

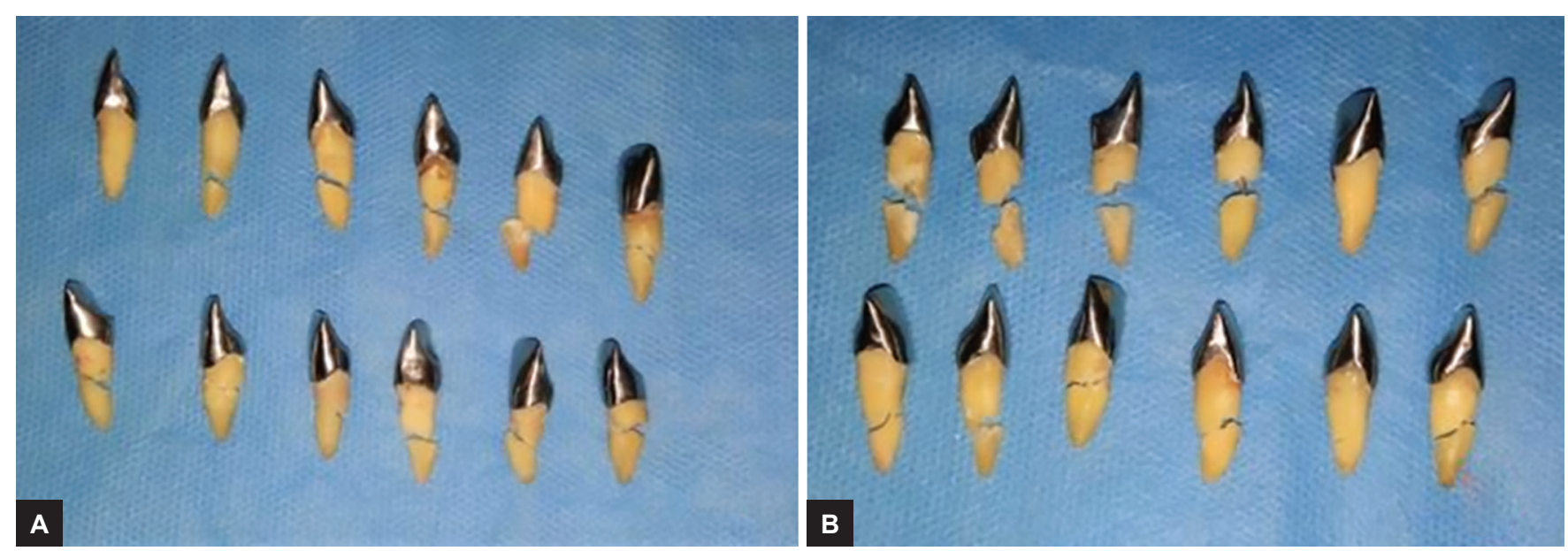

Figs 4A and B: Type of fracture in Ni-Cr (A) and NPG (B) groups

\section{RESULTS}

The mean fracture strength was $731.179 \pm 327.47 \mathrm{~N}$ in $\mathrm{Ni}-\mathrm{Cr}$ and $1411.89 \pm 313.56 \mathrm{~N}$ in the NPG group (Table 1). Considering the difference of $706.321 \mathrm{~N}$ between the two groups and standard error of $136.97 \mathrm{~N}$ as well as the distribution of fracture strength values in the Ni-Cr and NPG groups and $95 \%$ confidence interval, the difference was significant between the two groups $(p<0.001)$ (Graph 1$)$. Evaluation of the type of fracture revealed that in all specimens, fracture occurred below the CEJ and was therefore, irreparable (Fig. 4).

\section{DISCUSSION}

This study assessed the fracture strength of endodontically treated teeth restored with Ni-Cr and NPG post and cores after cyclic loading. The type of fracture was also determined. The results showed that the fracture strength of teeth restored with NPG post and core was significantly higher than that of teeth restored with $\mathrm{Ni}-\mathrm{Cr}$ post and core.
In molar teeth, due to the presence of adequate dentin and application of axial loads, the use of post is not often necessary for retention of the core ${ }^{27}$ and they are often restored with amalgam or composite. ${ }^{12}$ However, in single-rooted teeth, especially incisors that are under off-axial loads, the use of casting post and cores has been the gold standard for decades. ${ }^{27}$ When a large amount of anterior tooth structure is lost, tooth restoration with casting post and core is performed. In restoration of teeth under lateral loads, the use of fiber carbon, woven fiber, and glass fiber is not recommended. ${ }^{12}$ Moreover, in these teeth, metal posts show higher fatigue resistance than fiber-reinforced composite or zirconia posts. Thus, these posts are preferred to nonmetal ones. ${ }^{48}$

Martinez-Insua et a ${ }^{69}$ compared the fracture strength of single rooted teeth restored with cast metal gold post and cores, fiber carbon, and composite cores. The results showed that the fracture strength of teeth restored with metal casting posts was higher than the others. The mean fracture strength of both groups was lower than the mean fracture strength of NPG and Ni-Cr groups, which may 
be due to the type of the used resin cement, application of static load immediately after mounting of specimens and inadequate standardization of them. Hatzikyriakos et $\mathrm{al}^{70}$ evaluated 154 posts and cores in 150 patients; 69 teeth were restored with screw posts, para posts, and composite cores and 33 teeth were restored with casting posts and cores. After 3 years of follow-up, the success of treatment of anterior teeth restored with casting post and core was $93 \%$ compared with $89.9 \%$ for the other groups; these findings are in line with our results. Sirimai et $\mathrm{al}^{71}$ compared the vertical root fracture resistance of six post and core systems including prefabricated and casting posts and showed that teeth restored with custom casting posts and cores yielded the highest fracture strength.

In 1987, NPG was introduced as a new alloy. In addition to the advantages of its casting method, it revealed more favorable properties compared with other alloys. ${ }^{35}$ This alloy has a closer modulus of elasticity than that of dentin. It was also suggested and used for the fabrication of post and cores; however, studies regarding the fracture strength of teeth restored with NPG posts are limited. ${ }^{23}$

Pereira et $\mathrm{al}^{72}$ compared the fracture strength of 50 canine teeth restored with NPG casting posts and cores with prefabricated stainless steel posts. Five groups were studied. Group I was the control group with no coronal structure that received NPG casting post and core. Group II had no coronal structure; groups III to V had 1, 2, and $3 \mathrm{~mm}$ of ferrule respectively, and were restored with prefabricated stainless steel posts and resin cores and subjected to static load at $45^{\circ}$ angle. The fracture strength of groups I and II was significantly higher than that of other groups. It should be noted that the mean fracture strength of teeth in their study was much lower than the values obtained in our study, which may be due to the following reasons:

- No standardization of specimens

- Unequal canal preparation

- Static load application only

In their study, group I showed root fracture while most specimens in other groups showed fracture in the resin part.

When the fracture load and compressive stress are applied to the rigid post, the peak local stress is created in the root, which will lead to root fracture. ${ }^{73}$ When a post and core system with high modulus of elasticity is subjected to loading, a small crack with slow propagation rate is created at the post-cementum-dentin interface and when the post-dentin bond is lost, the post becomes mobile in the root and serves as a wedge. The energy concentrated in the post is transferred to dentin and leads to root fracture. ${ }^{69,70}$

In a study by Barcellos et $\mathrm{al}^{63}$ the fracture strength of endodontically treated teeth restored with intracanal posts and the effect of post system and dentin thickness were evaluated. A total of 70 maxillary canine teeth were divided into 7 groups $(n=10)$. One group served as the control and the other groups were restored with fiber posts, fiber posts reinforced with composite and cast Ni-Cr posts with 1 and $2 \mathrm{~mm}$ of root thickness. Full metal crowns were fabricated and subjected to 250,000 cycles (cyclic loading). Static load was applied until fracture. The fracture strength of fiber posts reinforced with composite was significantly higher than that of fiber posts and casting posts. No significant association was noted between the type of post and the remaining tooth structure. The mean fracture strength of Barcellos Ni-Cr casting post was lower than that in the current study, which may be due to inadequate stability of casting post and core after cementation (specimens remained in place by finger pressure for 20 seconds). Most dental fractures in casting post and core group were irreparable while in the other two groups, fractures were reparable and the type of fracture in the casting post group was similar to the type of fracture in our study. Another study demonstrated that the majority of fractures in teeth restored with casting posts were vertical root fractures. ${ }^{72}$

Sadeghi ${ }^{29}$ showed that canine teeth restored with $\mathrm{Ni}-\mathrm{Cr}$ casting posts and cores had significantly higher fracture strength than zirconia fiber and quartz groups; however, $92 \%$ of fractures occurred in the tooth structure.

Pereira et $\mathrm{al}^{74}$ indicated that NPG casting posts with $10 \mathrm{~mm}$ length had higher fracture strength. The mean fracture strength of the groups was not reported in their study. The tooth length was reported to be in the range of 15 to $18 \mathrm{~mm}$ while they were all cut at $15 \mathrm{~mm}$ length. They reported the breakage of some specimens during cyclic loading, which they thought might be due to errors in the conduction of the test. Haghighi and Jahromy ${ }^{25}$ compared the fracture strength of endodontically treated maxillary second premolars with two types of casting posts; 45 premolars were divided into three groups $(\mathrm{n}=10)$ of (I) restored with NPG post and core; (II) restored with Ni-Cr post and core, and (III) no post and core, restored with amalgam. Static load was applied to the buccal cusp at a crosshead speed of $0.5 \mathrm{~mm} / \mathrm{min}$ at $45^{\circ}$ angle until fracture. The results showed that the fracture strength of teeth restored with NPG was significantly higher than that of teeth restored with $\mathrm{Ni}-\mathrm{Cr}$. Moreover, the results showed that fracture mainly occurred in the root of teeth restored with Ni-Cr and NPG posts, while in teeth restored with amalgam, fracture occurred mainly in core. The aforementioned study reported lower fracture strength of teeth restored without post and core compared with those restored with casting post and core. Also, the fracture strength of teeth restored with NPG post was higher than that of teeth restored with $\mathrm{Ni}-\mathrm{Cr}$ post. The 
mean fracture strength of NPG and Ni-Cr groups in their study was lower than the mean fracture strength of NPG and Ni-Cr groups in the study, which may be due to the lack of placing a crown, as crowns significantly increase the fracture strength of teeth.

Khaledi et $\mathrm{al}^{5}$ assessed the fracture strength of teeth restored with NPG and Ni-Cr posts and cores. A total of 40 maxillary central incisors were cut $2 \mathrm{~mm}$ above their CEJ and divided into two groups $(n=20)$. Both groups were subjected to static loading at a crosshead speed of $0.5 \mathrm{~mm} / \mathrm{min}$ at $45^{\circ}$ angle to determine the fracture strength. The fracture strength of Ni-Cr group was found to be significantly higher than that of the NPG group. Their findings were different from ours, which may be attributed to the fact that the teeth were not standardized in buccolingual direction (the teeth were standardized only in mesiodistal dimension and root length). Moreover, in their study, crowns were not placed and cyclic loading was not performed. The fracture strength reported in their study was even lower than that reported in other studies for $\mathrm{Ni}-\mathrm{Cr}$ alloys.

No fracture occurred in the posts, crowns, or acrylic resins in our study. Debonding of crowns or extrusion of specimen from the acrylic did not occur either. All specimens showed the root fracture. As the masticatory load for the anterior teeth is on average $222 \mathrm{~N},{ }^{3}$ all fractures in our study occurred in loads higher than the physiologic threshold. ${ }^{30,75}$ It means that these fractures do not occur normally under physiologic loads in the oral cavity and thus, both alloys can be successfully used for tooth restoration in clinical setting. ${ }^{30}$ All fractures occurred in the root below the CEJ and were irreparable, which is in agreement with the results of Haghighi and Jahromy. ${ }^{25}$ In other studies, most fractures in the casting post and core groups were irreparable. ${ }^{63,72}$

In this study, cyclic loading was performed at a rate corresponding to 1 year clinical service. Higher cycles of and conduct of thermocycling can better simulate the oral environment. Future studies are required with the use of ceramic crowns. Also, in vitro studies are required on the disadvantages of NPG, such as corrosion. Future clinical studies with long-term follow-ups are also recommended to cast a final judgment in this respect.

Due to superior mechanical properties and higher fracture strength, NPG post and core seems to be a more suitable choice than $\mathrm{Ni}-\mathrm{Cr}$ for the restoration of severely damaged, endodontically treated anterior teeth (taking into account $2 \mathrm{~mm}$ of tooth height for the ferrule effect).

\section{REFERENCES}

1. Giovani AR, Vansan LP, de Sousa Neto MD, Paulino SM. In vitro fracture resistance of glass-fiber and cast metal posts with different lengths. J Prosthet Dent 2009 Mar;101(3):183-188.
2. Jindal S, Jindal R, Gupta K, Mahajan S, Garg S. Comparative evaluation of the reinforcing effect of different post systems in the restoration of endodontically treated human anterior teeth at two different lengths of post space preparation-an in vitro study. J Dent (Tehran) 2013 Mar;10(2):124-133.

3. Soundar SI, Suneetha TJ, Angelo MC, Kovoor LC. Analysis of fracture resistance of endodontically treated teeth restored with different post and core system of variable diameters: an in vitro study. J Indian Prosthodont Soc 2014 Jun;14(2):144-150.

4. Toksavul S, Zor M, Toman M, Güngör MA, Nergiz I, Artunc C. Analysis of dentinal stress distribution of maxillary central incisors subjected to various post-and-core applications. Oper Dent 2006 Jan-Feb;31(1):89-96.

5. Khaledi AA, Sheykhian S, Khodaei A. Evaluation of retention of two different casting post-core systems and fracture resistance of the restored teeth. J Dent (Shiraz) 2015 Jun;16(2):121-128.

6. Gutmann JL. The dentin-root complex: anatomic and biologic considerations in restoring endodontically treated teeth. J Prosthet Dent 1992 Apr;67(4):458-467.

7. Fokkinga WA, Le Bell AM, Kreulen CM, Lassila LV, Vallittu PK, Creugers NH. Ex vivo fracture resistance of direct resin composite complete crowns with and without posts on maxillary premolars. Int Endod J 2005 Apr;38(4):230-237.

8. Hussey DL, Killough SA. A survey of general dental practitioners' approach to the restoration of root-filled teeth. Int Endod J 1995 Mar;28(2):91-94.

9. Carter JM, Sorensen SE, Johnson RR, Teitelbaum RL, Levine MS. Punch shear testing of extracted vital and endodontically treated teeth. J Biomech 1983 Feb;16(10):841-848.

10. Schwartz RS, Robbins JW. Post placement and restoration of endodontically treated teeth: a literature review. J Endod 2004 May;30(5):289-301.

11. Steele GD. Reinforced composite resin foundations for endodontically treated teeth. J Prosthet Dent 1973 Nov;30(5): 816-819.

12. Rosenstiel, SF.; Land, MF.; Fujimoto, J. Contemporary fixed prosthodontics. 5th ed. St. Louis (MO): Elsevier; 2016. pp. 278-293.

13. Fernandes AS, Shetty S, Coutinho I. Factors determining post selection: a literature review. J Prosthet Dent 2003 Dec;90(6):556-562.

14. Tikku AP, Chandra A, Bharti R. Are full cast crowns mandatory after endodontic treatment in posterior teeth? J Conserv Dent 2010 Oct;13(4):246-248.

15. Ratnakar P, Bhosgi R, Metta KK, Aggarwal K, Vinuta S, Singh N. Survey on restoration of endodontically treated anterior teeth: a questionnaire based study. J Int Oral Health 2014 Nov-Dec;6(6):41-45.

16. Pierrisnard L, Bohin F, Renault P, Barquins M. Coronoradicular reconstruction of pulpless teeth: a mechanical study using finite element analysis. J Prosthet Dent 2002 Oct;88(4):442-448.

17. Sorensen JA, Martinoff JT. Clinically significant factors in dowel design. J Prosthet Dent 1984 Jul;52(1):28-35.

18. Makade CS, Meshram GK, Warhadpande M, Patil PG. A comparative evaluation of fracture resistance of endodontically treated teeth restored with different post core systems-an in-vitro study. J Adv Prosthodont 2011 Jun;3(2):90-95.

19. Hegde J, Ramakrishna, Bashetty K, Srirekha, Lekha, Champa. An in vitro evaluation of fracture strength of endodontically treated teeth with simulated flared root canals restored 
with different post and core systems. J Conserv Dent 2012 Jul;15(3):223-227.

20. Sreedevi S, Sanjeev R, Raghavan R, Abraham A, Rajamani T, Govind GK. An in vitro study on the effects of post-core design and ferrule on the fracture resistance of endodontically treated maxillary central incisors. J Int Oral Health 2015 Aug;7(8):37-41.

21. Naumann M, Koelpin M, Beuer F, Meyer-Lueckel H. 10-year survival evaluation for glass-fiber-supported postendodontic restoration: a prospective observational clinical study. J Endod 2012 Apr;38(4):432-435.

22. Gómez-Polo M, Llidó B, Rivero A, Del Rio J, Celemín A. A 10-year retrospective study of the survival rate of teeth restored with metal prefabricated posts versus cast metal posts and cores. J Dent 2010 Nov;38(11):916-920.

23. Rosenstiel, SF.; Land, MF.; Fujimoto, J. Contemporary fixed prosthodontics. 3rd ed. St. Louis (MO): Mosby; 2001. pp. 272-312, 771 .

24. Stegaroiu R, Yamada H, Kusakari H, Miyakawa O. Retention and failure mode after cyclic loading in two post and core systems. J Prosthet Dent 1996 May;75(5):506-511.

25. Haghighi ZB, Jahromy AM. Comparison of fracture strength of endodontically treated teeth restored with two different cast metallic post systems. J Dent Biomater 2014 Sep;1(2):45-49.

26. Smith CT, Schuman NJ, Wasson W. Biomechanical criteria for evaluating prefabricated post-and-core systems: a guide for the restorative dentist. Quintessence Int 1998 May;29(5):305-312.

27. Zhi-Yue L, Yu-Xing Z. Effects of post-core design and ferrule on fracture resistance of endodontically treated maxillary central incisors. J Prosthet Dent 2003 Apr;89(4):368-373.

28. Hansen PA, LeBlanc M, Cook NB, Williams K. The quality of post and cores made using a reduce-time casting technique. Oper Dent 2009 Nov-Dec;34(6):709-715.

29. Sadeghi M. A comparison of the fracture resistance of endodontically treated teeth using three different post systems. J Dent (Tehran) 2006 Feb;3(2):69-76.

30. Rippe MP, Santini MF, Bier CA, Baldissara P, Valandro LF. Effect of root canal preparation, type of endodontic post and mechanical cycling on root fracture strength. J Appl Oral Sci 2014 Jun;22(3):165-173.

31. Shillingburg, HT. Fundamentals of fixed prosthodontics. 3th ed. Chicago (IL): Quintessence Pub. Co.; 1997. p. 40.

32. Colley IT, Hampson EL, Lehman ML. Retention of post crowns. An assessment of the relative efficiency of posts of different shapes and sizes. Br Dent J 1968;124(2):63-69.

33. Creugers NH, Mentink AG, Fokkinga WA, Kreulen CM. 5 -year follow-up of a prospective clinical study on various types of core restorations. Int J Prosthodont 2005 Jan-Feb;18(1): 34-39.

34. Rathke A, Meisohle D. Cyclic loading of incisors restored with different post systems. J Oral Hyg Health 2014 Aug;2(4):1-4.

35. Hayashi M, Takahashi Y, Imazato S, Ebisu S. Fracture resistance of pulpless teeth restored with post-cores and crowns. Dent Mater 2006 May;22(5):477-485.

36. Dave Crume, K. The gold alternative. Fairfield (CA): Aalba Dent Inc.; 2011. [cited 2013 Jan 1]. Available from: http:// aalbadent.com/products/crown-bridge-alloys-fmc/npg

37. Ganley, CZ.; Donhauser, M. 4all. Liechtenstein:Ivoclar Vivadent AG; 1923. [cited 2016 Oct 4]. Available from: http://www. ivoclarvivadent.com/en/products/alloys/predominantlybase-alloys/nickel-chromium/4all.
38. McLaren JD, McLaren CI, Yaman P, Bin-Shuwaish MS, Dennison JD, McDonald NJ. The effect of post type and length on the fracture resistance of endodontically treated teeth. J Prosthet Dent 2009 Mar;101(3):174-182.

39. Dilmener FT, Sipahi C, Dalkiz M. Resistance of three new esthetic post-and-core systems to compressive loading. J Prosthet Dent 2006 Feb;95(2):130-136.

40. Zhang YX, Zhang WH, Lu ZY, Wang KL. Fracture strength of custom-fabricated Celay all-ceramic post and core restored endodontically treated teeth. Chin Med J (Engl) 2006 Nov;119(21):1815-1820.

41. Rosenstiel, SF.; Land, MF.; Fujimoto, J. Contemporary fixed prosthodontics. 4th ed. St. Louis (MO): Mosby Elsevier; 2006.

42. Behnaz, H.; Shafagh, I. Dental anatomy and morphology. Iran: Shayan Nemoodar; 2010.

43. Jindal S, Jindal R, Mahajan S, Dua R, Jain N, Sharma S. In vitro evaluation of the effect of post system and length on the fracture resistance of endodontically treated human anterior teeth. Clin Oral Investig 2012 Dec;16(6):1627-1633.

44. Gouharian R, Asadzadeh Aghdaei N. Evaluation of the fracture strength of the post-crowned teeth with and without ferrule. J Mashhad Dent School 2006 Summer;30(1-2):117-124.

45. Soares PV, Santos-Filho PCF, Martins LR, Soares CJ. Influence of restorative technique on the biomechanical behavior of endodontically treated maxillary premolars. Part I: fracture resistance and fracture mode. J Prosthet Dent 2008 Jan;99(1):30-37.

46. da Silva NR, Raposo LH, Versluis A, Fernandes-Neto AJ, Soares CJ. The effect of post, core, crown type, and ferrule presence on the biomechanical behavior of endodontically treated bovine anterior teeth. J Prosthet Dent 2010 Nov;104(5):306-317.

47. Akbari M, Javad Moghaddas M, Majidinia S. Effect of thermomechanical load cycling on the fracture strength of upper central incisor restored with three different types of glass-fiber posts. J Dent Med 2014 Jun;27(2):84-90.

48. Ng CC, Dumbrigue HB, Al-Bayat MI, Griggs JA, Wakefield CW. Influence of remaining coronal tooth structure location on the fracture resistance of restored endodontically treated anterior teeth. J Prosthet Dent 2006 Apr;95(4):290-296.

49. Goto Y, Nicholls JI, Phillips KM, Junge T. Fatigue resistance of endodontically treated teeth restored with three dowel-andcore systems. J Prosthet Dent 2005 Jan;93(1):45-50.

50. Salameh Z, Sorrentino R, Ounsi HF, Sadig W, Atiyeh F, Ferrari M. The effect of different full-coverage crown systems on fracture resistance and failure pattern of endodontically treated maxillary incisors restored with and without glass fiber posts. J Endod 2008 Jul;34(7):842-846.

51. Shillingburg,HT.;Sather,DA.;Wilson,EL.;Cain,JR.;Mitchell,DL.; Blanco, LJ.; Kessler, JC. Fundamentals of fixed prosthodontics. 4th ed. Hanover Park (IL): Quintessence Pub.; 2012.

52. Bassir MM, Labibzadeh A, Mollaverdi F. The effect of amount of lost tooth structure and restorative technique on fracture resistance of endodontically treated premolars. J Conserv Dent 2013 Sep;16(5):413-417.

53. Shamseddine L, Eid R, Homsy F, Elhusseini H. Effect of tapering internal coronal walls on fracture resistance of anterior teeth treated with cast post and core: in vitro study. J Dent Biomech 2014 Aug;5:1758736014547550.

54. Balkaya MC, Birdal IS. Effect of resin-based materials on fracture resistance of endodontically treated thin-walled teeth. J Prosthet Dent 2013 May;109(5):296-303.

55. Shayegh SS, Moghaddam KN, Khoroshy M, Khoroshy F. The effect of luting agent on the fracture resistance of root canal 
treated teeth restored with casting post. Iran Endod J 2006 Winter;1(4):133-136.

56. Mezzomo E, Massa F, Suzuki RM. Fracture resistance of teeth restored with 2 different post-and-core designs fixed with 2 different luting cements: an in vitro study. Part II. Quintessence Int 2006 Jun;37(6):477-484.

57. Preuss A, Rosentritt M, Frankenberger R, Beuer F, Naumann M. Influence of type of luting cement used with all-ceramic crowns on load capability of post-restored endodontically treated maxillary central incisors. Clin Oral Investig 2008 Jun;12(2):151-156.

58. Fraga RC, Chaves BT, Mello GS, Siqueira JF Jr. Fracture resistance of endodontically treated roots after restoration. J Oral Rehabil 1998 Nov;25(11):809-813.

59. Yaman SD, Alaçam T, Yaman Y. Analysis of stress distribution in a maxillary central incisor subjected to various post and core applications. J Endod 1998 Feb;24(2):107-111.

60. Jung SH, Min KS, Chang HS, Park SD, Kwon SN, Bae JM. Microleakage and fracture patterns of teeth restored with different posts under dynamic loading. J Prosthet Dent 2007 Oct;98(4):270-276.

61. Ahmadzadeh A, Mousavi N, Neshati A, Dabaghi F, Askari A. An in vitro study of resistance to vertical fracture in restored teeth of four types of post and core systems. Jundishapur Sci Med J 2013 Nov;12(5):531-540.

62. Tan PL, Aquilino SA, Gratton DG, Stanford CM, Tan SC, Johnson WT, Dawson D. In vitro fracture resistance of endodontically treated central incisors with varying ferrule heights and configurations. J Prosthet Dent 2005 Apr;93(4):331-336.

63. Barcellos RR, Correia DP, Farina AP, Mesquita MF, Ferraz CC, Cecchin D. Fracture resistance of endodontically treated teeth restored with intra-radicular post: the effects of post system and dentine thickness. J Biomech 2013 Oct;46(15): 2572-2577.

64. de Oliveira JA, Pereira JR, Lins do Valle A, Zogheib LV. Fracture resistance of endodontically treated teeth with different heights of crown ferrule restored with prefabricated carbon fiber post and composite resin core by intermittent loading. Oral Surg Oral Med Oral Pathol Oral Radiol Endod 2008 Nov;106(5):e52-e57.
65. Kampe T, Haraldson T, Hannerz H, Carlsson GE. Occlusal perception and bite force in young subjects with and without dental fillings. Acta Odontol Scand 1987 Apr;45(2):101-107.

66. De Boever JA, McCall WD Jr, Holden S, Ash MM Jr. Functional occlusal forces: an investigation by telemetry. J Prosthet Dent 1978 Sep;40(3):326-333.

67. Kern M, Strub JR, Lü XY. Wear of composite resin veneering materials in a dual-axis chewing simulator. J Oral Rehabil 1999 May;26(5):372-378.

68. Evangelinaki E, Tortopidis D, Kontonasaki E, Fragou T, Gogos C, Koidis P. Effect of a crown ferrule on the fracture strength of endodontically treated canines restored with fiber posts and metal-ceramic or all-ceramic crowns. Int J Prosthodont 2013 Jul-Aug;26(4):384-387.

69. Martinez-Insua A, da Silva L, Rilo B, Santana U. Comparison of the fracture resistances of pulpless teeth restored with a cast post and core or carbon-fiber post with a composite core. J Prosthet Dent 1998 Nov;80(5):527-532.

70. Hatzikyriakos AH, Reisis GI, Tsingos N. A 3-year postoperative clinical evaluation of posts and cores beneath existing crowns. J Prosthet Dent 1992 Apr;67(4):454-458.

71. Sirimai S, Riis DN, Morgano SM. An in vitro study of the fracture resistance and the incidence of vertical root fracture of pulpless teeth restored with six post-and-core systems. J Prosthet Dent 1999 Mar;81(3):262-269.

72. Pereira JR, de Mendonça Neto T, Porto VC, Pegoraro LF, do Valle AL. Influence of the remaining coronal structure on the resistance of teeth with intraradicular retainer. Braz Dent J 2005 Sep-Dec;16(3):197-201.

73. Heydecke G, Peters MC. The restoration of endodontically treated, single-rooted teeth with cast or direct posts and cores: a systematic review. J Prosthet Dent 2002 Apr;87(4):380-386.

74. Pereira JR, Ribeiro Neto EM,PamatoS, do ValleAL, dePaula VG, Vidotti HA. Fracture resistance of endodontically treated teeth restored with different intraradicular posts with different lengths. Braz J Oral Sci 2013 Jan-Mar;12(1):1-4.

75. Lyons MF, Baxendale RH. A preliminary electromyographic study of bite force and jaw-closing muscle fatigue in human subjects with advanced tooth wear. J Oral Rehabil 1990 Jul;17(4):311-318. 